\title{
Feto maternal outcome in eclampsia after 28 weeks of pregnancy: vaginal delivery versus caesarean section
}

\author{
Bhawna Madan* \\ Department of Obstetrics and Gynecology, R.N.T. Medical College, Udaipur, Rajasthan, India \\ Received: 14 June 2017 \\ Revised: 10 July 2017 \\ Accepted: 19 July 2017

\section{*Correspondence:} \\ Dr. Bhawna Madan, \\ E-mail: docbhawna27@gmail.com \\ Copyright: () the author(s), publisher and licensee Medip Academy. This is an open-access article distributed under \\ the terms of the Creative Commons Attribution Non-Commercial License, which permits unrestricted non-commercial \\ use, distribution, and reproduction in any medium, provided the original work is properly cited.
}

\begin{abstract}
Background: Eclampsia is the occurrence of convulsions or coma unrelated to other cerebral condition with signs and symptoms of preeclampsia. Objective of present study was the comparison of maternal and fetal outcome of women with more than 28 weeks gestation complicated by antepartum eclampsia when terminated either by caesarean section or by vaginal delivery.

Methods: 200 Women with more than 28 weeks of gestation with antepartum eclampsia were studied from admission to discharge or death. Depending upon the mode of delivery, they were divided into two groups: C.D. group. Where caesarean section was performed and V.D. group, where vaginal delivery was carried out. Maternal and Perinatal outcome were studied in the two groups and compared.

Results: Of the 200 cases, caesarean section was done in $40 \%$ of the cases, while vaginal delivery was carried out in $60 \%$. Maternal complications were seen in $15 \%$ of the cases in the C.D group and $60 \%$ of the cases in the V.D. group. Maternal deaths occurred in none of the case in the C.D group and in $33 \%$ of the cases in the V.D group. The incidence of live births, still births and neonatal deaths was $87.8 \%, 2.43 \%$ and $9.75 \%$ respectively in the C.D group, while it was $49.16 \%, 45.16 \%$ and $9.67 \%$ in the V.D group The Corrected perinatal mortality was $9.75 \%$ in the C.D group and $43.55 \%$ in the V.D group. Apgar score less than 5 at 1 minute was seen in $35 \%$ cases in the C.D group and $82.35 \%$ cases in the V.D group. $30 \%$ of the cases in the C.D group and $76.47 \%$ of the cases in the V.D group required NICU admission.

Conclusions: Timely caesarean section reduces maternal and Perinatal mortality and improves their outcome in antepartum eclampsia, especially in women with more than 28 weeks of pregnancy.
\end{abstract}

Keywords: Antepartum eclampsia, Caesarean section, Convulsion, Vaginal delivery

\section{INTRODUCTION}

Eclampsia is the occurrence of convulsions or coma unrelated to other cerebral condition with signs and symptoms of preeclampsia. Diagnosis is usually established by the presence of hypertension. ${ }^{1}$ Proteinuria and edema with the history of convulsion with or without unconsciousness.Eclampsia is an important cause of maternal morbidity and mortality as well as a significant contributor to higher incidences of perinatal morbidity and mortality. ${ }^{2}$

The convulsions in eclampsia are usually generalized tonic clonic in nature and may appear at any time i.e.

- Antepartum eclampsia (before onset of labor) 35$40 \%$

- Intrapartum (during labor) $15-20 \%$ 


\section{- $\quad$ Postpartum (after labor) 35-40\%}

Fits occurring beyond 7 days of delivery rules out eclampsia. Incidence of eclampsia in india is around 0.179 to $3.7 \%$.

Eclampsia is essenlitally a disesase of poor and a product of ignorance and neglect. It is characterised by premonitory stage, tonic stage, clonic stage and stage of coma \& when fits occur in quick successions it is called status eclampticus. ${ }^{3}$

Mean gestational age of eclampsia is found to be 29 to 36 weeks. A significant group of symptoms are often a warning of an impending attack like severe headache, dimness of vision or temporary blindness, severe epigastric pain, vomiting and considerable rise in blood pressure usually preceeds the occurrence of fits. ${ }^{4}$

Eclampsia is seen as a from of hypertensive encephalopathy in the context of those Pathological events that lead to preeclampsia. ${ }^{5}$

Placental hypoperfusion is a key feature of the process accompanied by increased vascularity of maternal vasculature to pressor agents. ${ }^{6}$ Typically, an eclamptic seizure will not lead to lasting brain damage, however intracranial haemorrhage may occur.

Faced with this reality, a plan of management has to be evolved, one thing has been proved beyond doubt that termination of pregnancy, remove the basic cause of the disease, keeping this in view an attempt has been made in the present study to ascertain whether caesarean section delivery has any distinct advantage over vaginal delivery in lowering maternal and perinatal deaths. ${ }^{7}$

\section{METHODS}

The study period extended from May 2013 to September 2014, a period of 16 months. The study was done in Rajkiya Mahila Chikitsalya, J. L. N. Medical College, Ajmer, Rajasthan, India.

A total of 200 patients were studied. Patients with the following criteria were selected for the study.

- Primi gravida

- Duration of gestation more than 28 weeks

- Antepartum eclampsia.

\section{Exclusion criteria}

- Patients with pregnancy induced hypertension without eclampsia.

- Patients with epilepsy or other causes of convulsions with pregnancy.

The 200 patients were studied by dividing them into two groups for comparative analysis.
- The first group consisted of patients in whom conservative obstetric management and delivery per vaginum was carried out and was called the V.D. group.

- The second group consisted of patients in whom lower segment caesarean section was carried out due to eclampsia and varied associated indications and was called the C.D. group.

On admission, a detailed history was taken regarding:

- The name, age, socioeconomic status, religion and address of the patient.

- The antenatal checkups.

- The duration of gestation in terms of months of amenorrhea.

- The time of onset of convulsion, total number of convulsions, interval between convulsions, duration of each convulsion, the time of last convulsion, history of loss of consciousness and history of frothing, tongue bite, passing urine/ stools during the convulsions.

- Premonitory symptoms like headache, epigastric pain, nausea, vomiting and blurred vision.

- Any history of pain abdomen, trauma, per vaginal leak or bleeding

- Obstetric, menstrual, past, family and personal history

- Any nature of treatment taken before hospitalization.

A rapid general examination was subsequently made noting the grade of consciousness of the patient, temperature, pulse rate, respiratory rate, blood pressure, presence of edema, evidence of tongue bite, condition of the heart, state of the lungs and knee jerk.

A detailed obstetric examination was conducted noting the height of the uterus, presence, frequency and duration of uterine contraction, lie and presentation of the fetus, relation of the presenting part to the brim and the rate and regularity of the fetal heart.

Vaginal examination was done and the condition of the cervix - position, consistency, dilatation, effacement and station of the presenting part i.e., Bishop's score was noted. Presence of bag of membrane and adequacy of the pelvis was also noted. ${ }^{8}$ Bladder was catheterized and urine output was noted.

IV line was started and 1 pint of Ringer lactate was given for hydration. Investigations were sent for complete hemogram, urine analysis, blood grouping and Rh-typing, renal and liver function tests and coagulation profile.

\section{RESULTS}

200 women were studied with gestational age more than 28 weeks with antepartum eclampsia. The C.D group had incidence of $40 \%$ and that of V.D group $60 \%$. Higher 
incidence of antepartum eclampsia was in 20-25 yrs of age group in both the study groups maximum incidence of antepartum eclampsia was seen between $36-40$ weeks in both groups.

Table 1: Bishop's Score on admission.

\begin{tabular}{|lllllll|}
\hline Bishop's score & V.D. grouj & \multicolumn{2}{c}{ C.D. group } & \multicolumn{3}{c|}{ Total } \\
\hline 0 (Unfavourable) & No. of cases & $\mathbf{\%}$ & No. of cases & \% & No. of cases & $\%$ \\
\hline 1-5 (Unfavourable) & 14 & 11.66 & 18 & 22.50 & 32 & 16.00 \\
\hline 6-13 (favourable) & 54 & 43.33 & 36 & 45.00 & 88 & 44.00 \\
\hline Total & 120 & 45.00 & 26 & 32.50 & 80 & 40.00 \\
\hline
\end{tabular}

Most of the cases had thrown less than 5 convulsions. Bishop's Score was unfavourable in $67.5 \%$ of cases C.D group $54.99 \%$ of cases in V.D group. $75 \%$ of vaginal deliveries were induced. $70 \%$ of cases in the C.D group were delivered within $12 \mathrm{hrs}$ of first fit while $31.66 \%$ of cases in the V.D group did so.

Table 2: Perinatal morbidity.

\begin{tabular}{|l|lcll|}
\hline $\begin{array}{l}\text { Perinatal } \\
\text { outcome }\end{array}$ & $\begin{array}{l}\text { V.D. group } \\
\text { No. of } \\
\text { cases }\end{array}$ & $\%$ & $\begin{array}{l}\text { C.D. group } \\
\text { No. of } \\
\text { cases }\end{array}$ & $\%$ \\
\hline $\begin{array}{l}\text { Apgar }<5 \text { at } \\
1 \text { minute }\end{array}$ & $\begin{array}{l}56 \text { out of } \\
68\end{array}$ & 82.35 & $\begin{array}{l}28 \text { out of } \\
80\end{array}$ & 35.00 \\
\hline $\begin{array}{l}\text { Need for } \\
\text { resuscitation }\end{array}$ & $\begin{array}{l}30 \text { out of } \\
68\end{array}$ & 44.11 & $\begin{array}{l}8 \text { out of } \\
80\end{array}$ & 10.00 \\
\hline $\begin{array}{l}\text { Need for } \\
\text { NICU stay }\end{array}$ & 52 out of & 76.47 & $\begin{array}{l}24 \text { out of } \\
80\end{array}$ & 30.00 \\
\hline
\end{tabular}

Bishop's score was unfavourable in $67.5 \%$ of cases in the C.D. group and in $54.99 \%$ of cases in the V.D. group.

Table 3: Convulsion delivery interval.

\begin{tabular}{|l|llll|}
\hline $\begin{array}{l}\text { Convulsion } \\
\text { delivery } \\
\text { interval (hrs) }\end{array}$ & $\begin{array}{l}\text { V.D. group } \\
\text { No. of } \\
\text { cases }\end{array}$ & $\%$ & \multicolumn{3}{l|}{$\begin{array}{l}\text { C.D. group } \\
\text { No. of }\end{array}$} & $\%$ \\
\hline 0-6 hrs & 6 & 5.00 & 20 & 25.00 \\
\hline 6-12 hrs & 32 & 26.66 & 36 & 45.00 \\
\hline 12-18 hrs & 40 & 33.33 & 14 & 17.50 \\
\hline 18-24 hrs & 26 & 21.66 & 4 & 5.00 \\
\hline >24 hrs & 16 & 13.33 & 6 & 7.50 \\
\hline Total & 120 & 100.00 & 80 & 100.00 \\
\hline
\end{tabular}

$\chi^{2}=16.64 ; \mathrm{p}<0.001$, Highly significant

Live birth rate was $87.8 \%$ in the C.D. group and $45.16 \%$ in the V.D. group. Corrected perinatal mortality rate was $9.75 \%$ in the C.D. group and $45.33 \%$ in the V.D. group. NICU admission rate was $30 \%$ in the C.D. and $76.4 \%$ in the V.D. group. Incidence of complication was $15 \%$ in the C.D. and $60 \%$ in the V.D. group. The incidence of perinatal mortality and maternal complication increased with increase in the total number of convulsion, convulsion -delivery and induction- delivery interval.

\section{DISCUSSION}

Eclampsia a dreaded complication in pregnancy is still associated with a great deal of maternal and fetal loss. ${ }^{1}$ Earlier, the conventional treatment of eclampsia entailed a conservative approach with the use of sedative, tranquilizers, anticonvulsants and anti-hypentensives to be followed by induction and caesarean action was reserved for highly selective cases. ${ }^{8}$ Now with advancements in the field of anaesthesiology, caesarean section promises reassuring maternal and perinatal outcome. $^{2}$

Mean duration of stay in NICU was 3.08 days in C.D. group and 7.34 days in V.D. group. The incidence of still births was $2.43 \%$ and $45.16 \%$ respectively and neonatal death was $9.75 \%$ and $9.67 \%$ respectively. For all birth weights perinatal mortality was found to be lesser in the C.D. group. Perinatal mortality increased in proportion to increase in the number of convulsions, increase in induction delivery interval and increase in first convulsion- delivery interval. ${ }^{5}$

Maternal complications were more in V.D. group. Acute renal failure was seen in $3.33 \%$ of cases of V.D. group. ${ }^{9}$ Abruptio placenta was seen in $3.33 \%$ of cases of V.D. group, Hakewadi quoted an incidence of $19.6 \%$. Hepatic failure was seen in $1.66 \%$ of cases in V.D. group. Transient blindness was encountered in $6.66 \%$ of cases in V.D. group Postpartum psychosis were seen in 2 cases in C.D. group urinary tract infection was seen in $2.5 \%$ cases of in C.D. and $1.66 \%$ of cases in V.D. group. Maternal mortality occurred in $3.33 \%$ of cases in V.D. group while no maternal deaths in the C.D. group.

\section{CONCLUSION}

Prompt termination of pregnancy by caesarean section reduces maternal and perinatal mortality and morbidity improves maternal outcomes by reducing complication and also improves perinatal outcome with better oneminute Apgar scores and reduced NICU stay. Caesarean section should be done at the optimum time and not as a last resort when conservative management has failed in 
eclampsia especially in primigravidas after $28^{\text {th }}$ week of pregnancy.

Funding: No funding sources Conflict of interest: None declared

Ethical approval: The study was approved by the Institutional Ethics Committee

\section{REFERENCES}

1. Dutta DC. Textbook of Obstetrics, $4^{\text {th }} \mathrm{Ed}$, Calcutta, New Central Book Agency Pvt Ltd. Chapter 17;1998:234-54.

2. Williams Obstetrics. $22^{\text {nd }}$ Ed. McGraw Hill Co. Inc. chapter 40. 2005:761-808.

3. Pal B, Geeta N, Vivek P. A study of eclampsia. J Obstet Gynecol. 1996;46(1):34-39.

4. Bhattacharya PK, Purkayastha S, Basu M, Robinsanath M. Caesarean section in eclampsia: Still a dilemma. J Obstet Gynecol India. 1992;42(1):5155 .

5. Majhi AK, Chakraborty PS, Mukhopadhyay A. Eclampsia present scenario in a referral medical college hospital. J Obstet Gynecol India. 2001;51(3):143-7.

6. Kamilya G, Bharracharyya SK, Mukherji J. Changing trends in the management of eclampsia from a teaching hospital. J Indian Med Assoc. 2005;103(5):132-5.

7. Mundle S, Mullik I. Risk factors in pregnancy outcome in eclampsia. Abstracts Free Communication Papers, $42^{\text {nd }}$ All India congress of Obstetrics and Gynecology. 1998.

8. Pritchard JA, Cunningham FG, Mason RA. Coagulation changes in frequency and pathogenesis. Am J Obstet Gynecol. 1976;124:855.

9. Bansal V. Maternal and perinatal outcome in Eclampsia. Abstract, free communication papers, $42^{\text {nd }}$ All India Congress of Obstetrics and Gynecology. 1998.

Cite this article as: Madan B. Feto maternal outcome in eclampsia after 28 weeks of pregnancy: vaginal delivery versus caesarean section. Int $\mathbf{J}$ Reprod Contracept Obstet Gynecol 2017;6:3875-8. 